\title{
Inhalt des vierten Bandes. ${ }^{1}$
}

Darstellung von Gasen (RAMbay, NoYes und GUYE) . . . . . . . . . . . 1 Apparate gur Gasentwicklung (StäHLER und KVRT) . . . . . . . . . 129 Darstellung und Behandlung kolloider Btoffe (The Svedrero) . . . . . 142 Darstellung von Metallen und Legierungen (Ropolfi und Weiss) . . . . 213 Regulinische schwer schmelzbare Metalle (Weiss) . . . . . . . . . 284 Ceritmetalle (Werss) . . . . . . . . . . . . . . . . . . . . . 293

Thermitreaktionen (PBANDTL) . . . . . . . . . . . . . . . . . . 315 Darstellung und Untersuchung phosphorescierender Stoffe (TомA8cHez) - 327 Mineralsynthese (ErTEL) . . . . . . . . . . . . . . . . . . . . 391 Kristallgüchtung (EıтвL) . . . . . . . . . . . . . . . . . . . . 448 Zusammenstellung einiger anorganischen Stoffe, die im Zustand der größten Relnheit dargestellt worden sind (LlbRBo) . . . . . . . . 473 Nachtrag and Berichtigungen . . . . . . . . . . . . . . . . 488 Autorenregister zum vierten Band . . . . . . . . . . . . . . . 489 General-Sachregister zum ersten bis vierten Band . . . . . . . . . 497

1 Am Anfang der einzelnen Beiträge befinden sich ausführlichere Inhaltsangaben. 
